\title{
Differential responses to high- and low-dose ultraviolet-B stress in tobacco Bright Yellow-2 cells
}

\section{OPEN ACCESS}

Edited by:

Kaoru Okamoto Yoshiyama, Kyoto Sangyo University, Japan

Reviewed by:

Jun Hidema,

Tohoku University, Japan

Gary Gardner

University of Minnesota, USA

*Correspondence:

Shinya Takahashi, Alliance for Research on North Africa, University of Tsukuba, Tennodai 1-1-1,

Tsukuba, Ibaraki 305-8577, Japan takahashi.shinya.fp@u.tsukuba.ac.jp

Specialty section: This article was submitted to Plant Physiology, a section of the journal Frontiers in Plant Science

Received: 29 January 2015 Paper pending published: 17 February 2015 Accepted: 31 March 2015 Published: 21 April 2015

Citation: Takahashi S, Kojo KH, Kutsuna N, Endo M, Toki S, Isoda $H$ and

Hasezawa S (2015) Differential responses to high- and low-dose ultraviolet- $B$ stress in tobacco Bright Yellow-2 cells. Front. Plant Sci. 6:254. doi: 10.3389/fpls.2015.00254

\author{
Shinya Takahashi ${ }^{1,2,3 *}$, Kei H. Kojo ${ }^{1,4}$, Natsumaro Kutsuna ${ }^{1,4}$, Masaki Endo ${ }^{5}$, \\ Seiichi Toki ${ }^{5}$, Hiroko Isoda ${ }^{2,3}$ and Seiichiro Hasezawa ${ }^{1}$
}

${ }^{1}$ Department of Integrated Biosciences, Graduated School of Frontier Sciences, The University of Tokyo, Kashiwa, Japan, ${ }^{2}$ Alliance for Research on North Africa, University of Tsukuba, Tsukuba, Japan, ${ }^{3} \mathrm{Ph}$. D. Program in Life Science Innovation, University of Tsukuba, Tsukuba, Japan, ${ }^{4}$ LPixel Inc., Bunkyo-ku, Japan, ${ }^{5}$ Plant Genome Engineering Research Unit, Agrogenomics Research Center, National Institute of Agrobiological Sciences, Tsukuba, Japan

Ultraviolet (UV)-B irradiation leads to DNA damage, cell cycle arrest, growth inhibition, and cell death. To evaluate the UV-B stress-induced changes in plant cells, we developed a model system based on tobacco Bright Yellow-2 (BY-2) cells. Both low-dose UV-B (low UV-B: $740 \mathrm{~J} \mathrm{~m}^{-2}$ ) and high-dose UV-B (high UV-B: $2960 \mathrm{~J} \mathrm{~m}^{-2}$ ) inhibited cell proliferation and induced cell death; these effects were more pronounced at high UV-B. Flow cytometry showed cell cycle arrest within 1 day after UV-B irradiation; neither low- nor high-UV-B-irradiated cells entered mitosis within $12 \mathrm{~h}$. Cell cycle progression was gradually restored in low-UV-B-irradiated cells but not in high-UV-B-irradiated cells. UV-A irradiation, which activates cyclobutane pyrimidine dimer (CPD) photolyase, reduced inhibition of cell proliferation by low but not high UV-B and suppressed high-UV-B-induced cell death. UV-B induced CPD formation in a dose-dependent manner. The amounts of CPDs decreased gradually within 3 days in low-UV-B-irradiated cells, but remained elevated after 3 days in high-UV-B-irradiated cells. Low UV-B slightly increased the number of DNA single-strand breaks detected by the comet assay at 1 day after irradiation, and then decreased at 2 and 3 days after irradiation. High UV-B increased DNA fragmentation detected by the terminal deoxynucleotidyl transferase dUTP nick end labeling assay 1 and 3 days after irradiation. Caffeine, an inhibitor of ataxia telangiectasia mutated (ATM) and ataxia telangiectasia and Rad3-related (ATR) checkpoint kinases, reduced the rate of cell death in high-UV-B-irradiated cells. Our data suggest that low-UV-B-induced CPDs and/or DNA strand-breaks inhibit DNA replication and proliferation of BY-2 cells, whereas larger contents of high-UV-B-induced CPDs and/or DNA strand-breaks lead to cell death.

Keywords: BY-2, cell cycle, cell death, checkpoint, DNA damage, ultraviolet-B

\section{Introduction}

Ultraviolet (UV)-B radiation (280-320 nm), a component of sunlight, is unavoidable for plants because of their sessile life. This radiation may lead to growth inhibition or even cell death. UV-B induces formation of pyrimidine photodimers, such as cyclobutane pyrimidine dimers (CPDs) and pyrimidine (6-4) pyrimidone photoproducts, and thus inhibits DNA replication and 
transcription, increases the number of mutations, and induces cell cycle arrest and cell death (Lo et al., 2005; de Lima-Bessa et al., 2008). Higher plants have multiple DNA repair mechanisms (Mannuss et al., 2012). For example, under light, the UV$\mathrm{B}$-induced photodimers are repaired by photolyases specific to each photodimer; mammals have no homologous genes (Ahmad et al., 1997; Nakajima et al., 1998; Hidema et al., 2000; Takeuchi et al., 2007). Photolyases are activated by UV-A/blue light (Hada et al., 2000; Teranishi et al., 2008). The dark repair involves nucleotide excision repair and base excision repair mechanisms (Mannuss et al., 2012). Severe damage by ionizing radiation and UV-B radiation may also result in generation of DNA strand breaks, which are repaired by the homologous recombination, non-homologous end joining, and microhomologymediated end joining systems (Ries et al., 2000; Amiard et al., 2013). Endoreduplication in response to UV-B irradiation has been reported; whether it may play a protective role in UV-B tolerance is unknown (Radziejwoski et al., 2011).

In mammals, UV-B radiation interferes with cell cycle progression (Garinis et al., 2005; Ortolan and Menck, 2013). In Arabidopsis, photodimer formation causes cell cycle arrest and inhibits hypocotyl elongation (Biever et al., 2014). Arabidopsis shares several DNA damage checkpoint mechanisms with mammals and yeast (Yoshiyama et al., 2013b). The phosphatidyl3-kinase family members, ataxia telangiectasia mutated (ATM) and ataxia telangiectasia and Rad3-related (ATR) kinases, are required for initiation of DNA damage responses (DDRs) (Roy, 2014). ATM mainly responds to DNA double-strand break (DSB) induced by ionizing radiation and chemical mutagens (Garcia et al., 2003). ATR mainly responds to single-stranded DNA (ssDNA) and replication stressors, such as hydroxyurea, aphidicolin, and UV stress (Culligan et al., 2004). In Arabidopsis, ATR, and its partner protein ATRIP are involved in tolerance to UV-B stress (Culligan et al., 2004; Sakamoto et al., 2009). Mammalian ATR and ATM phosphorylate checkpoint kinases 1 and 2 (CHK1 and $\mathrm{CHK} 2$ ) and activate the p53 transcription factor (Cimprich and Cortez, 2008; Shiloh and Ziv, 2013). However, plants have no homologs of p53, CHK1, or CHK2. In Arabidopsis, suppressor of gamma 1 (SOG1) functions in genotoxic stress-induced cell death and checkpoint mechanisms (Yoshiyama et al., 2009, 2013a; Adachi et al., 2011), and in UV-B-induced programmed cell death and growth retardation (Furukawa et al., 2010; Biever et al., 2014).

Although inhibition of cell cycle progression by UV-B in Arabidopsis root cells synchronized with hydroxyurea has been reported (Jiang et al., 2011), the details of UV-B-induced production of photodimers and their role in growth inhibition, cell cycle arrest, and cell death in higher plants remain unclear, in part because of the lack of appropriate experimental models.

Tobacco bright yellow-2 (BY-2) cells are non-green because they lack developed chloroplasts. They are larger than Arabidopsis cells, have high proliferation rates (80-100-fold per week) and are easy to synchronize for cell cycle progression studies (Nagata et al., 1992; Kumagai-Sano et al., 2006). BY-2 cells have also been used to study responses to pathogens, oxidative stress, and genotoxic stress, including UV stress (Perennes et al., 1999; Kadota et al., 2005; Sano et al., 2006; Lytvyn et al., 2010; Smetana et al.,
2012). They are highly suitable for observations of cell death and organelle alterations in response to stresses (Higaki et al., 2007).

In this study, to investigate cellular responses to UV-B irradiation, we developed a model using BY-2 cells. Low-dose UV$B$ irradiation inhibited cell proliferation and induced cell death with low frequency, whereas high doses induced cell death. This difference may have been caused by differences in the amounts of UV-B-induced photodimers, DNA strand breaks, or both. We also found that ATM, ATR, or both kinases mediated UV-B stress-induced cell death.

\section{Materials and Methods}

\section{Plant Material and Culture Conditions}

Tobacco BY-2 (Nicotiana tabacum L. cv. Bright Yellow 2) suspension-cultured cells were maintained by weekly dilution (1:95) with modified Linsmaier and Skoog (LS) medium as described by Kumagai-Sano et al. (2006). Cell suspensions were agitated on a rotary shaker at $130 \mathrm{rpm}$ at $27^{\circ} \mathrm{C}$ in the dark.

\section{UV Treatments}

A UV-B fluorescent lamp (FL20SE; Kyokko Denki, Japan, Supplemental Figure 1) was used. Seven day-old BY-2 cells were diluted (1:40) with LS medium (Perennes et al., 1999) and incubated as above for $1 \mathrm{~h} ; 10 \mathrm{~mL}$ of cell suspension was transferred into a plastic Petri dish, covered with a UV29 quartz glass filter (cut-off of <290 nm; Hoya Glass, Japan) (Ioki et al., 2008), and exposed to $1.6 \mathrm{~W} \mathrm{~m}^{-2}$ of UV-B for up to $31 \mathrm{~min}$. In some experiments, immediately after UV-B irradiation, UV-A $\left(18.3 \mathrm{~W} \mathrm{~m}^{-2}\right)$ was supplied by a UV-A fluorescent lamp (FL20S-BL; Toshiba, Japan, Supplemental Figure 1) through the UV29 quartz glass filter for $30 \mathrm{~min}$. After irradiation, BY-2 cells were transferred to a flask and cultured with agitation under standard conditions. The intensities of UV-B and UV-A irradiation were measured by a MS-211-I UV photometer with a sensor specific to the UV-B and UV-A lamp spectrum (EKO Instruments, Japan).

\section{Fresh Weight Determination}

A 1-mL aliquot of cell suspension were transferred to microtubes and centrifuged for $30 \mathrm{~s}$ at $5000 \mathrm{rpm}$. Supernatants were removed by aspiration and pellets were weighed in at least three independent experiments.

\section{Dead Cell Counting}

Dead cells were detected by the Evans blue method as described by Ohno et al. (2011). In brief, cells from a 1-mL aliquot of suspension were collected by centrifugation, incubated with $0.05 \%$ Evans blue (Wako, Japan) for $10 \mathrm{~min}$ and then washed with water. Dead cells (stained blue) were counted under a microscope (BX51; Olympus, Japan). At least 500 cells were counted in each experiment.

\section{Flow Cytometry}

Flow cytometry was performed as described by Ohno et al. (2011). Frozen BY-2 cell pellets were chopped in extraction buffer with a sharp razor blade to extract the nuclei, filtered through 30 $\mu \mathrm{m}$ filters; isolated nuclei were stained with a CyStain UV Precise 
P kit (Partec, Germany). DNA content was determined with a Ploidy Analyzer (Partec).

\section{Synchronization of BY-2 Cells and Determination of Mitotic Index}

BY-2 cells were synchronized as described by Kumagai-Sano et al. (2006). Mitotic index was determined by counting $4^{\prime}$, 6-Diamidino-2-phenylindole, dihydrochloride (DAPI) stained nuclei using a fluorescence microscope (BX51). At least 300 cells were counted in each experiment.

\section{DNA Extraction and Detection of UV-Induced CPD Formation by ELISA}

Total genomic DNA was extracted from frozen BY-2 cell pellets using DNeasy Plant Mini Kit (QIAGEN, CA) and sam-

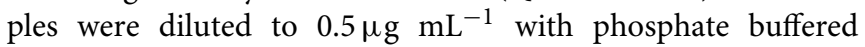
saline (PBS) buffer. CPD formation was measured by enzymelinked immuno-sorbent assay (ELISA) as previously described (Takeuchi et al., 1996; Takahashi et al., 2002) with slight modifications. Commercial monoclonal antibody BM12 (1:5000; Kyowa Medex Co., Japan) and ECL Anti-mouse IgG, Horseradish Peroxidase-linked Whole antibody (from sheep) (GE Healthcare, UK) were used and absorbance was measured at $492 \mathrm{~nm}$ by using a microplate reader (Viento nano; DS Pharma Biomedical, Japan).

\section{Detection of DNA Strand Breaks by Comet Assay}

Comet assay was performed as described by Menke et al. (2001) with modifications. In brief, frozen BY-2 cell pellets were chopped in PBS buffer with a razor blade to release the nuclei. The nuclei were filtered through the $30-\mu \mathrm{m}$ filters, mixed with Comet LM agarose, applied to CometSlide (CometAssay kit; Trevigen Inc., Germany) on a heating block at $42^{\circ} \mathrm{C}$; slides were incubated for $15 \mathrm{~min}$ at $4^{\circ} \mathrm{C}$ in the dark. The number of singlestrand breaks was measured according to the alkaline/neutral (A/N) protocol (Menke et al., 2001). Slides were incubated in $0.3 \mathrm{M} \mathrm{NaOH}, 5 \mathrm{mM}$ EDTA $(\mathrm{pH} \mathrm{13.5)}$ for $10 \mathrm{~min}$ at room temperature, equilibrated with $1 \times \mathrm{TBE}$ buffer $(3 \times 5 \mathrm{~min})$ at $4^{\circ} \mathrm{C}$ in the dark. Electrophoresis $(25 \mathrm{~V}, 6 \mathrm{~mA})$ was performed at room temperature in $1 \times \mathrm{TBE}$ for $20 \mathrm{~min}$. Then the slides were soaked in $1 \%$ Triton X-100 for $10 \mathrm{~min}, 70 \% \mathrm{EtOH}(2 \times$ $5 \mathrm{~min}), 99.5 \% \mathrm{EtOH}(2 \times 5 \mathrm{~min})$, dried at $37^{\circ} \mathrm{C}$ for $30 \mathrm{~min}$ and stained with SYBR Green Gold Nucleic Acid cell stain (Invitrogen-Life Technologies, CA). Images were captured using a fluorescence microscope (BX51). Comet tails were quantified using the KBI plug-in "Cometassay" for ImageJ software (http://hasezawa.ib.k.u-tokyo.ac.jp/zp/Kbi/ImageJKbiPlugins).

\section{Detection of DNA Fragmentation by TUNEL Assay}

Terminal deoxynucleotidyl transferase dUTP nick-end labeling (TUNEL) assay was performed according to the manufacturer's protocol (In Situ Cell Death Detection Kit, Fluorescein; Roche Diagnostics GmbH, Germany) with modifications. Samples were fixed in $4 \%$ paraformaldehyde buffered with PBS for $20 \mathrm{~min}$ at $4{ }^{\circ} \mathrm{C}$, and labeled with fluorescein. Fluorescein signals and DAPIstained cells were detected by using a fluorescence microscope.

\section{Caffeine Treatment}

Cells were treated with caffeine as described by Smetana et al. (2012). In brief, BY-2 cells were pretreated with $5 \mathrm{mM}$ caffeine for $1 \mathrm{~h}$, irradiated with high UV-B, cultured for $24 \mathrm{~h}$, and the dead cells were counted as described above.

\section{Statistical Analysis}

Student's $t$-test in Microsoft Excel 2007 software was used for statistical analysis.

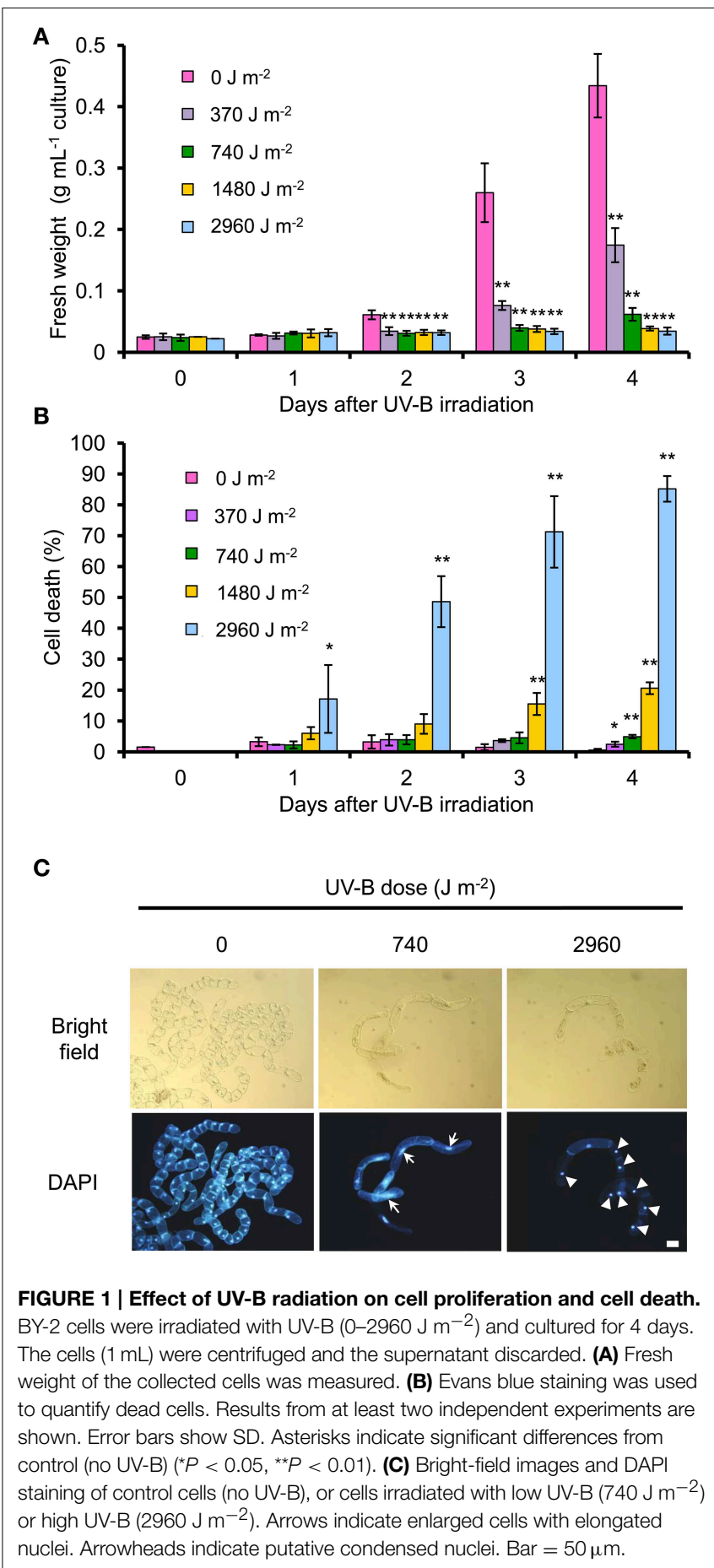




\section{Results}

\section{Effect of UV-B Irradiation on BY-2 Cell Proliferation and Death}

We determined how four different UV-B doses affect BY-2 cell proliferation and cell death. As an indicator of cell proliferation, we used fresh weight of centrifuged cell pellets. Cell proliferation was inhibited at 2 days after irradiation at all UV-B doses tested (Figure 1A). At 4 days after irradiation, the fresh weight of cells irradiated at 2960,1480 , and $740 \mathrm{~J} \mathrm{~m}^{-2}$ was $<15 \%$ of that of nonirradiated cells, whereas the fresh weight of cells irradiated at 370 $\mathrm{J} \mathrm{m}^{-2}$ was $41 \%$ of that of the control cells (Figure 1A). The number of dead cells reached $17 \%$ after UV-B irradiation at $2960 \mathrm{~J}$ $\mathrm{m}^{-2}$ at 1 day. At 4 days, it was $85 \%$ at $2960 \mathrm{~J} \mathrm{~m}^{-2}, 20.6 \%$ at 1480 $\mathrm{J} \mathrm{m}^{-2}$, and $<10 \%$ at $740 \mathrm{~J} \mathrm{~m}^{-2}$ and $370 \mathrm{~J} \mathrm{~m}^{-2}$ (Figure 1B).

Thus, we set two UV-B conditions, low UV-B $\left(740 \mathrm{~J} \mathrm{~m}^{-2}\right)$ to inhibit cell proliferation, and high UV-B $\left(2960 \mathrm{~J} \mathrm{~m}^{-2}\right)$ to inhibit cell proliferation and induce cell death. Low UV-B resulted in only a small number of dead cells but led to the enlargement of the cells and nuclei (Figure 1C). Cell enlargement and nuclear elongation may be caused by increasing the nuclear DNA content above 4C (Yasuhara and Kitamoto, 2014). Low UV-B-irradiated cells did not reach the nuclear DNA content of $8 \mathrm{C}$ (data not shown). High UV-B irradiation led to cytoplasm shrinkage and nuclear condensation in dead cells (Figure 1C).

\section{UV-B Irradiation Induces Cell Cycle Arrest in BY-2 Cells}

The DNA content of most BY-2 cells in the stationary phase was $2 \mathrm{C}$, indicating that most cells were at G1 phase before UV-B irradiation. At 1 day after low UV-B irradiation, the cell cycle was arrested at the $2 \mathrm{C}-4 \mathrm{C}$ transition (G1/S transition). At 3-4 days after UV-B irradiation, the number of cells at $4 \mathrm{C}$ (G2/M phase) increased but transition from $S$ to $\mathrm{G} 2 / \mathrm{M}$ phase and from $\mathrm{G} 2 / \mathrm{M}$ to G1 was slower than that of non-irradiated cells (Figure 2A). After high UV-B irradiation, almost all cells were arrested at $2 \mathrm{C}$ at 1 or 2 days, and only a small number of cells reached 4C (Figure 2A).

Next, we synchronized the cells at the $S$ phase by adding aphidicolin. In control cells, the mitotic index peaked at 7-9 h after aphidicolin release (Figure 2B). In low and high UV-Birradiated cells, no clear peak of mitotic index was detected within $12 \mathrm{~h}$ after aphidicolin release (Figure 2B). Thus, we concluded that low and high UV-B irradiation induced cell cycle arrest at G1 or S phase; cell cycle arrest at G2/M may be also induced at 3-4 days after low UV-B irradiation.

\section{UV-A Irradiation Suppresses Changes Induced by Low UV-B and Cell Death Induced by High UV-B Irradiation}

To examine the possibility of repair of UV-B-induced damage by activating a photolyase, we checked the effects of UV-A irradiation. A 30-min exposure to UV-A radiation immediately after UV-B irradiation partially prevented inhibition of cell proliferation induced by low UV-B (Figure 3A) and cell death induced by low and high UV-B (Figure 3B). The number of low UV-Birradiated cells with enlarged nuclei and increased cell volume decreased at 4 days after UV-A irradiation (Figure 3C).

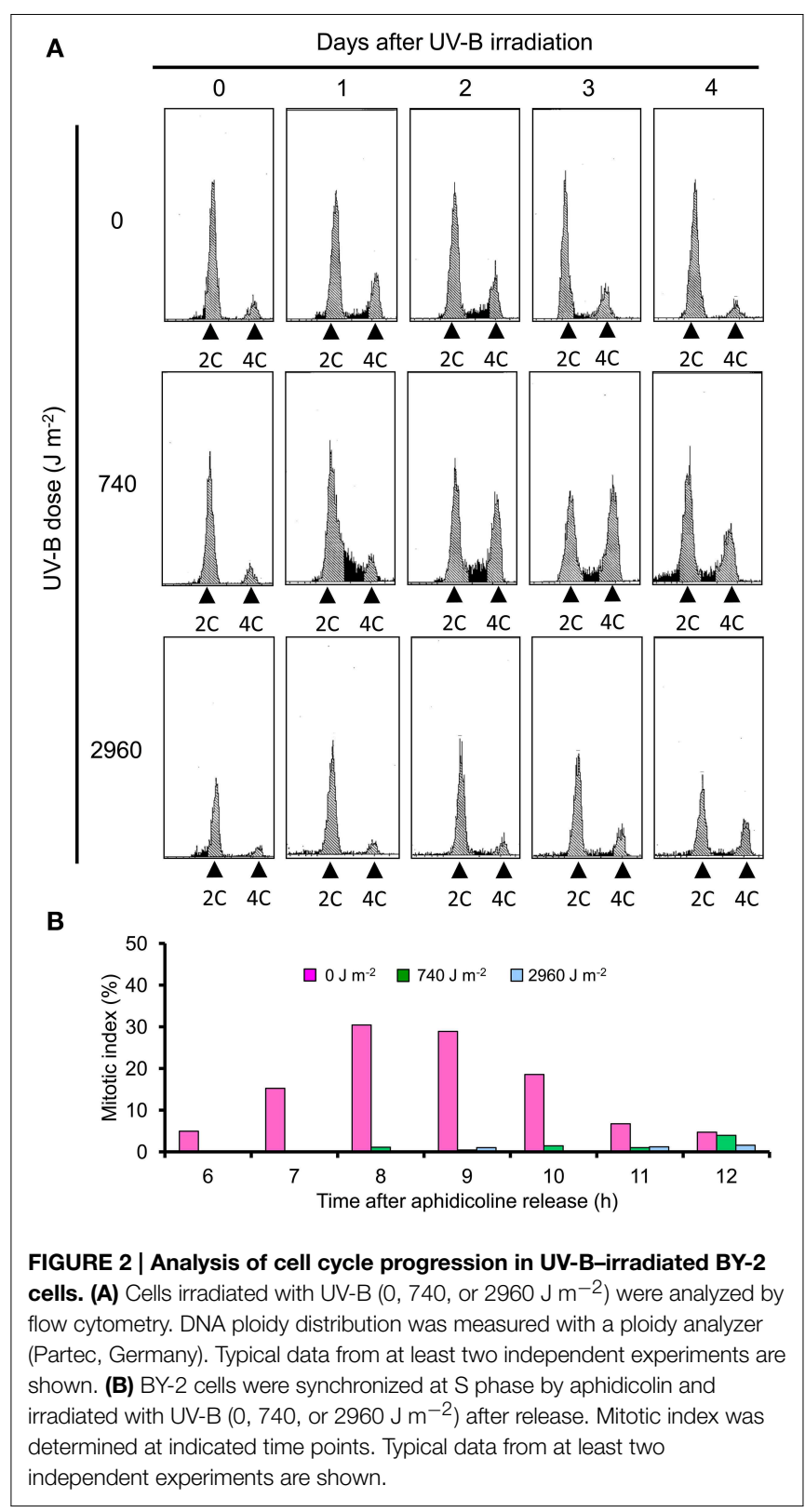

\section{UV-B Irradiation Induces CPD Formation, Which May Be Reduced by UV-A Irradiation}

Immediately after irradiation, the CPD amounts in high UV-Birradiated cells were approximately twice those in low UV-Birradiated cells. In low UV-B-irradiated cells, the CPD content decreased by approximately $66 \%$ at 4 days after irradiation. In high UV-B-irradiated cells, the CPD content decreased by $52 \%$ at 4 days after irradiation (Figure 4A, Supplemental Figure 2).

The CPD content in cells exposed to UV-A following low UV-B irradiation was decreased by half in comparison with control cells. In high UV-B-irradiated cells, the CPD content was also significantly reduced by UV-A irradiation and reached the level observed in low UV-B-irradiated cells without UV-A irradiation (Figure 4B). 

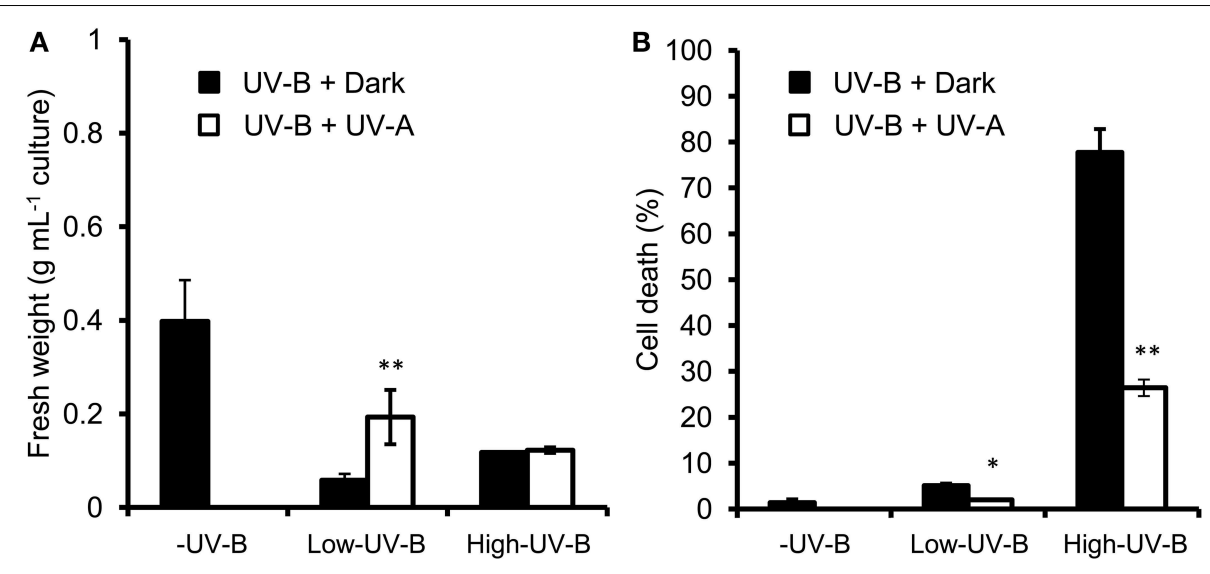

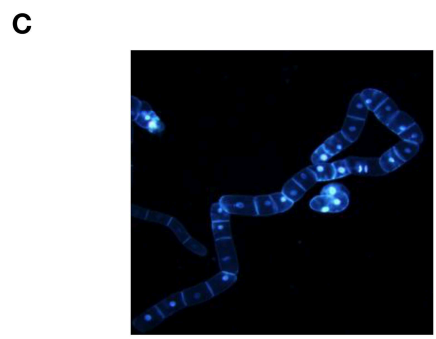

-UV-B

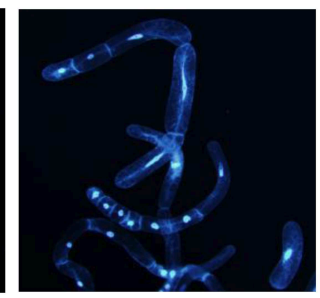

Low-UV-B + Dark

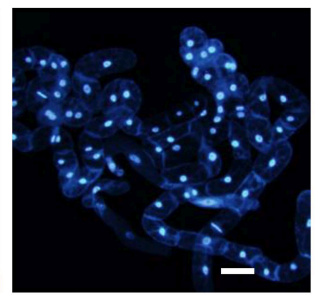

Low-UV-B
FIGURE 3 | Effects of UV-A radiation on UV-B-induced changes in cell proliferation and cell death. BY- 2 cells were irradiated with UV-B (0, 740, or $\left.2960 \mathrm{~J} \mathrm{~m}^{-2}\right)$, followed by 30-min incubation in the dark (UV-B + Dark) or 30 min UV-A irradiation (UVB + UVA). (A) Fresh weight; (B) the percentage of dead cells. Error bars in $(\mathbf{A}, \mathbf{B})$ show SD $(n=3)$. Asterisks indicate significant differences from the UV-B + Dark treatment $\left({ }^{\star} P<0.05,{ }^{\star \star} P<0.01\right)$. (C) DAPI-stained cells at $4 \mathrm{~d}$ after irradiation. Bar $=50 \mu \mathrm{m}$.

\section{UV-B Irradiation Induces DNA Strand Breaks in BY-2 Cells}

Immediately after irradiation with low or high UV-B, the number of single-strand breaks increased significantly. Single-strand breaks transiently increased at 1 day after low UV-B irradiation, and then gradually decreased at 2-3 days, whereas they continued to increase over 3 days after high UV-B irradiation (Figure 5). TUNEL assay detects fluorescent labeling of DNA strand breaks by using terminal deoxynucleotidyl transferase (TdT), which catalyzes the polymerization of labeled nucleotides to free $3^{\prime}-\mathrm{OH}$ DNA ends in a template-independent manner (Gavrieli et al., 1992). The TUNEL assay is often used to detect DNA fragmentation, including single-strand breaks and DSBs (Kwon et al., 2013). At 1 and 3 days after irradiation, TUNEL signals were detected in both low and high UV-B irradiated cells; the signals were observed more frequently in high UV-B-irradiated cells than in low UV-B-irradiated cells (Figure 6). These results suggest that low and high UV-B irradiation induces the single-strand breaks, and may cause DSB formation.

\section{High UV-B Irradiation Induces ATM and ATR Kinase-Mediated Cell Cycle Arrest and/or Cell Death in BY-2 Cells}

To confirm the roles of ATM and ATR kinases in the UV-B-induced cell death, we used their inhibitor, caffeine.
Pretreatment with caffeine for $1 \mathrm{~h}$ followed by high UV-B irradiation reduced cell death at $24 \mathrm{~h}$ (Figure 7 ). This result indicates that checkpoint signaling mediated by ATM, ATR, or both kinases is involved in high UV-B-induced cell death.

\section{Discussion}

UV-B radiation induces cell cycle arrest and cell death, yet how DNA damage triggers cell cycle arrest and cell death in plant cells remains unclear. In this study, we investigated the dosedependence of inhibition of cell proliferation and induction of cell death by UV-B in BY-2 cells.

\section{BY-2 Cells Irradiated with Low and High UV-B Show Different Damage Responses}

Low UV-B inhibited cell proliferation and induced cell death with low frequency. The low UV-B-induced CPDs were formed but declined within several days. The UV-A exposure immediately after low UV-B irradiation prevented inhibition of cell proliferation and reduced the CPD content. High UV-B induced inhibition of cell proliferation and cell death. High UV-B induced larger amounts of CPDs than low UV-B, and they declined although somewhat slower. The UV-A exposure immediately after high UV-B irradiation prevented cell death but did not 


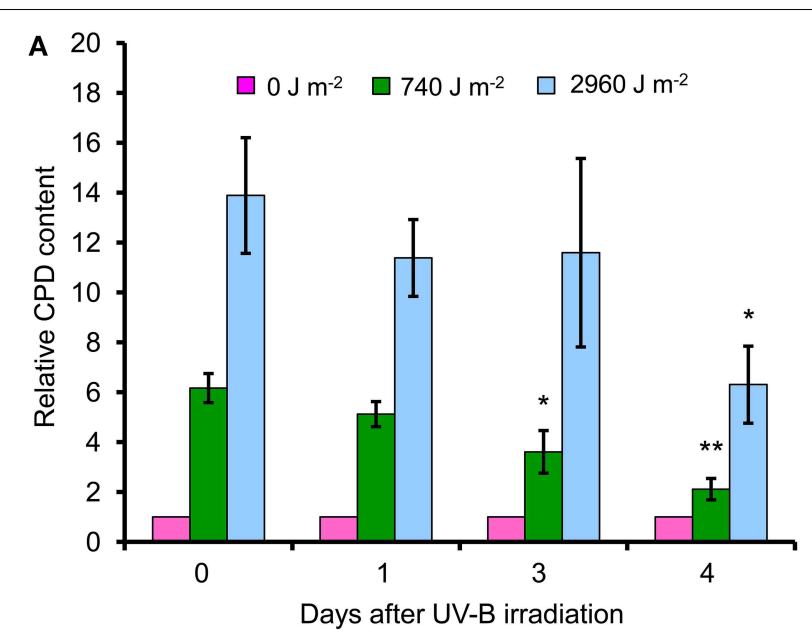

B

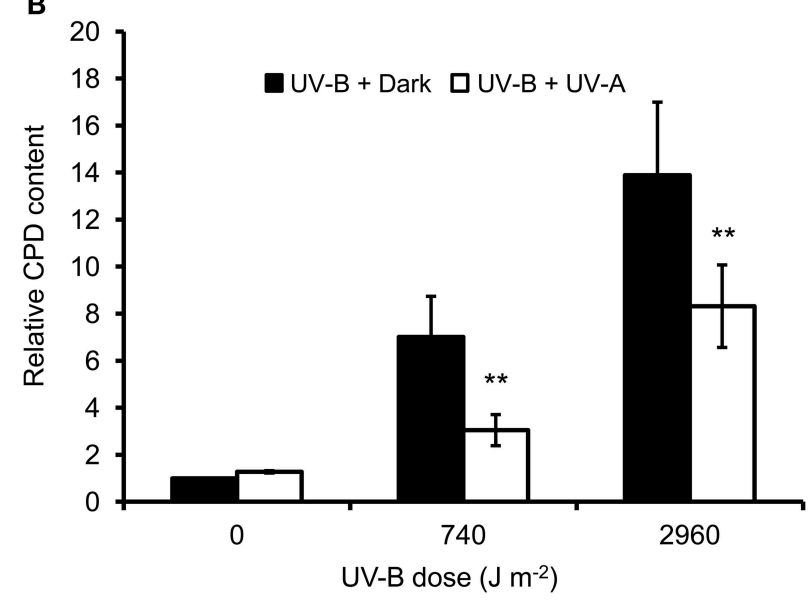

FIGURE 4 | Accumulation of cyclobutane pyrimidine dimers in UV-B-irradiated cells and reduction by UV-A radiation. Contents of cyclobutane pyrimidine dimers (CPDs) were measured by ELISA with CPD-specific antibody (BM12; Kyowa Medex Co., Japan). (A) The contents of CPD at $0,1,3$, and 4 days after UV-B irradiation relative to that in non-irradiated cells. Error bars show SD $(n=3)$. Asterisks indicate significant differences from the non-irradiated control $\left({ }^{*} P<0.05\right.$, $\left.{ }^{* *} P<0.01\right)$. (B) Amounts of CPDs in cells irradiated with UV-A immediately after UV-B exposure at indicated doses $\left(0,740\right.$, or $\left.2960 \mathrm{~J} \mathrm{~m}^{-2}\right)$ relative to those in cells irradiated only with $U V-B$ at 0 days after irradiation. Error bars show $S D$ $(n=3)$. Asterisks indicate significant differences from the UV-B + Dark treatment $\left({ }^{*} P<0.05,{ }^{* *} P<0.01\right)$.

prevent inhibition of cell proliferation. These results suggest a strong relationship between CPD formation and dose-dependent inhibition of cell proliferation and induction of cell death by UV-B.

In low UV-B-irradiated cells, CPDs were detected until 34 days, but cell proliferation and cell cycle progression were observed. In plants, translesion DNA synthesis is involved in UV-B tolerance (Sakamoto et al., 2003; Takahashi et al., 2005; Anderson et al., 2008). Translesion DNA synthesis-type DNA polymerases bypass DNA lesions and allow DNA synthesis to progress with DNA lesions. This mechanism might be functional in BY-2 cells.

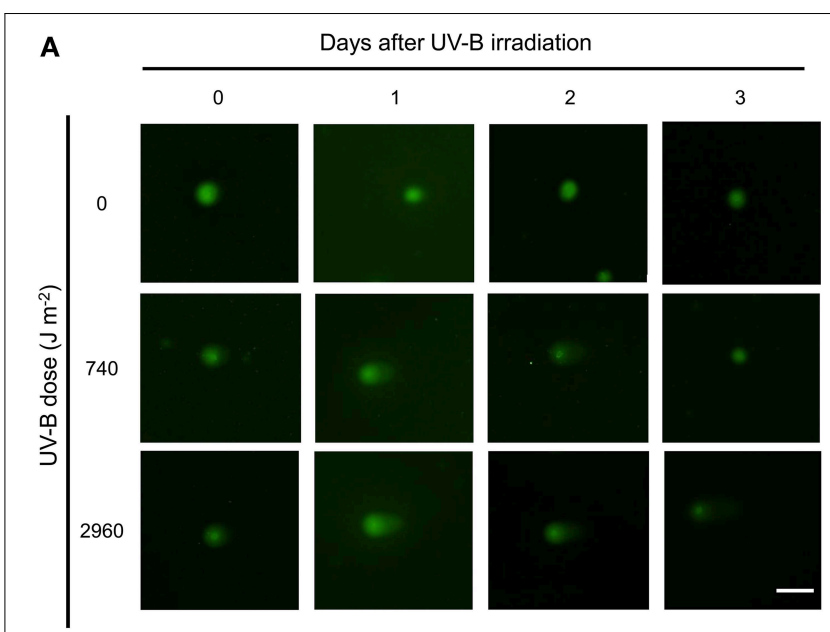

B

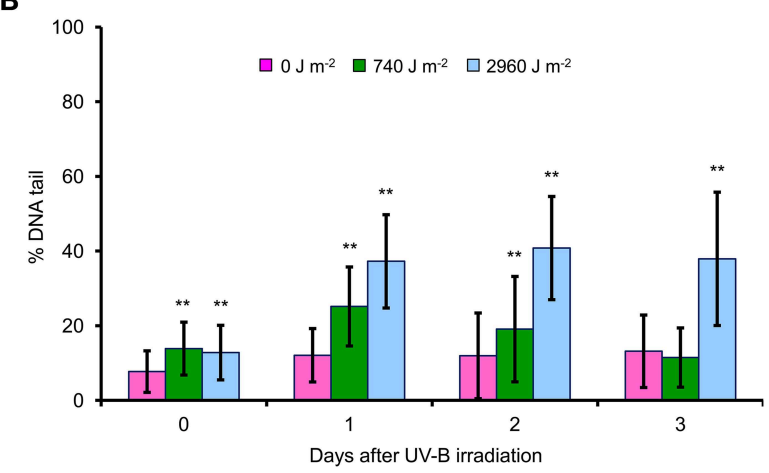

FIGURE 5 | Single-strand breaks induced by low- and high-dose UV-B irradiation. Frequencies of DNA strand breaks were measured by the comet assay (Menke et al., 2001). BY-2 cells were irradiated with UV-B (0, 740, or $2960 \mathrm{~J} \mathrm{~m}^{-2}$ ) and cultured for 3 days. Nuclei were assayed by using the alkaline/neutral protocol, which detects mainly single-strand breaks (Menke et al., 2001). (A) SYBR Green-stained nuclei at 1, 2, and 3 days after 0, 740, and $2960 \mathrm{~J} \mathrm{~m}^{-2}$ of UV-B irradiation. Bar $=100 \mu \mathrm{m}$. (B) DNA strand breaks were quantified by using the KBI plug-in "Cometassay" for ImageJ software and expressed as percentage of DNA in the tail. Error bars show SD. Asterisks indicate significant differences from control (no UV-B) $(P<0.01)$. Typical results from two independent experiments are shown.

\section{Low UV-B-Induced CPDs May Generate Transient single-Strand Breaks and Induce Cell Cycle Arrest}

Low UV-B irradiation led to transient single-strand breaks and cell cycle arrest during the G1 and S phases at 1-2 days. The amounts of CPDs and single-strand breaks were reduced and cell cycle progression restarted at 3-4 days after UV-B irradiation. In Arabidopsis, the ATR-mediated pathway provides tolerance to UV-B stress (Culligan et al., 2004; Sakamoto et al., 2009). DNA integrity may be restored by ATR recruitment and DNA lesion bypass activity (Furukawa et al., 2010; Curtis and Hays, 2011). The ATR-mediated pathway might be activated by the presence of single-strand breaks and trigger cell cycle arrest in our system.

In addition to cell cycle arrest during the G1 and S phases at 1-2 days after UV-B irradiation, many cells were arrested at the G2/M checkpoint at 2-3 days after UV-B irradiation. In 


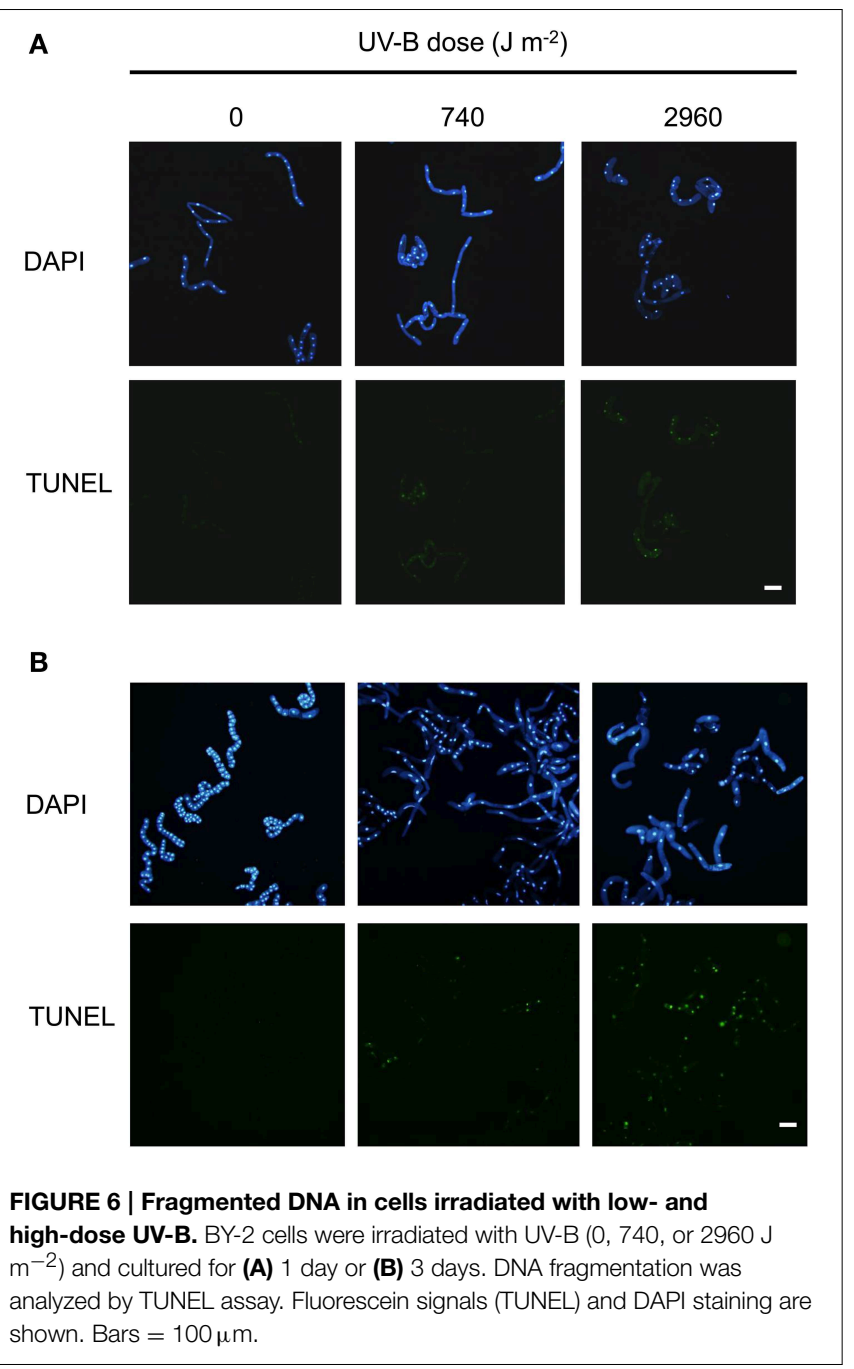

Arabidopsis roots, UV-B downregulates the expression of Histone $\mathrm{H} 4$ and $\mathrm{E} 2 \mathrm{Fa}$ (cell cycle progression markers), delays $\mathrm{CYCD} 3 ; 1$ (a positive factor in G1-to-S transition) expression, and upregulates the expression of KRP2 (a negative regulator of the G1to-S transition), suggesting that UV-B irradiation induces the G1-to-S arrest (Jiang et al., 2011). Molecular mechanisms of UV$\mathrm{B}$-induced cell cycle arrest are still mostly unknown. It is interesting to analyze the temporal expression of G1/S or G2/M-specific marker genes after UV-B irradiation.

\section{High UV-B Induces Large CPD Amounts, Persistent Single-strand Breaks, Permanent Cell Cycle Arrest, and High Rate of Cell Death}

High UV-B irradiation induced CPDs (twice as many as low UV-B did), single-strand breaks, and permanent cell cycle arrest at the G1/S transition. CPD accumulation may induce singlestrand breaks (and eventually DSBs), and prolonged presence of CPDs or single-strand breaks may accelerate cell death (Garinis et al., 2005; Lopes et al., 2006). In Arabidopsis root tip stemcell niches, programmed cell death induced by roughly 30,000 unrepaired photoadducts generated by UV-B irradiation was

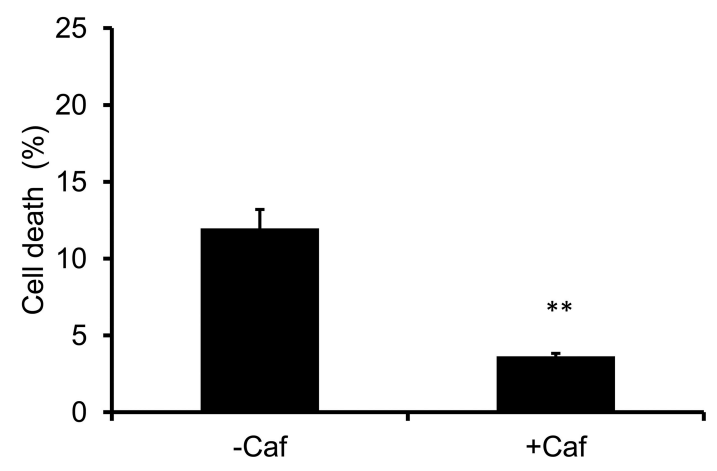

FIGURE 7 | Caffeine reduces cell death induced by high-dose UV-B. BY-2 cells pretreated with $5 \mathrm{mM}$ caffeine (+Caf) or without caffeine (-Caf) for $1 \mathrm{~h}$ were exposed to UV-B (2960 $\mathrm{J} \mathrm{m}^{-2}$ ) and cultured for $24 \mathrm{~h}$. Dead cells stained with Evans blue were counted. Error bars show SD $(n=3)$. Asterisks indicate a significant difference from - Caf $(P<0.01)$.

similar to that caused by $24 \mathrm{DSB}$ generated by gamma radiation (Furukawa et al., 2010). In Arabidopsis, the entry into S phase in the presence of ssDNA may generate DSBs due to collapse of DNA replication forks (Curtis and Hays, 2011). Thus, high UV$B$ may induce not only CPDs and single-strand breaks but DSB formation, and trigger cell death.

Among high UV-B-irradiated cells, TUNEL-positive cells were observed from the next day after irradiation; fewer TUNEL-positive cells were observed upon low UV-B irradiation. Bleomycin-treated BY-2 cells show paraptosis-type cell death without DNA fragmentation (Smetana et al., 2012), whereas BY-2 cells exposed to very high UV-B $\left(283 \mathrm{~kJ} \mathrm{~m}^{-2}\right)$ show apoptosistype programmed cell death that involves DNA fragmentation (Lytvyn et al., 2010). High UV-B-induced cell death observed in this study is likely apoptosis-like programmed cell death.

\section{Checkpoint Kinases, ATM and ATR, May Regulate UV-B-Induced Cell Death}

In our study, caffeine treatment reduced high UV-B-induced cell death. UV-B may activate both ATR-mediated and ATMmediated pathways (Furukawa et al., 2010). Because caffeine inhibits both ATR and ATM pathways, their relative contributions are unclear. In mammals, caffeine inhibits UV-B mediated ATR/Chk1 pathways and decreases the levels and phosphorylation of Cyclin B1, which mediates entry to mitosis (Conney et al., 2013). Whether this also takes place in plants is unclear. In the future, we will need to investigate which pathway contributes most to UV-B-induced cell death in BY-2 cells.

ATM and ATR kinase-mediated DDRs regulate programmed cell death (Fulcher and Sablowski, 2009). In Arabidopsis DDR mutants, UV-B-induced DNA strand breaks trigger ATM/ATR/SOG1-mediated cell death (Furukawa et al., 2010; Curtis and Hays, 2011). In this study, we directly observed the formation of UV-B-induced CPDs and transient formation of single-strand breaks. Their content may affect the survival vs. cell death choice in UV-B-irradiated BY-2 cells; at least, our data show that the ATM/ATR pathways mediate 
high UV-B-induced cell death and thus provide evidence for DDR-mediated UV-B-induced cell death in BY-2 cells.

\section{Advantages and Disadvantages of the BY-2 Cell Model for Studying UV-B Responses}

In green tissues, it may often be difficult to interpret the effects of UV-B on growth retardation because UV-B also affects photosynthesis (Allen et al., 1997; Takeuchi et al., 2002). Thus, the potential effects of UV-B on the cell cycle or signal transduction are difficult to distinguish from its direct effects on photosynthesis. As BY-2 cells are non-green, they do not pose these problems in studies of UV-B responses.

Non-green tissues, such as those of etiolated seedlings, might offer an advantage for investigations of photoregulation of light-responsive genes (Gardner et al., 2009). UV-B activates the phenylpropanoid pathway, which includes phenylalanine ammonia-lyase and chalcone synthase (CHS), and it serves to synthesize UV-B-absorbing compounds such as flavonoids (Kusano et al., 2011). This mechanism is mediated by the UVB-specific receptor UV-resistance 8 (UVR8) (Brown and Jenkins, 2008; Biever et al., 2014). It would be interesting to investigate the physiological roles of the UV-B-inducible flavonoid biosynthesis pathway in regulation of the cell cycle by using the BY-2 model system if the CHS and UVR8 genes are expressed in these cells.

Few studies of UV-B effects on plant cellular components are available (Lytvyn et al., 2010). In mammalian cells, UV$\mathrm{B}$ induces apoptosis by a mechanism that involves caspase8 activation and mitochondrial dysfunction (Takasawa et al., 2005). BY-2 cells are also good experimental tools for studying organelles, including mitochondria (Arimura et al., 2004; Sano et al., 2005; Higaki et al., 2007); it would be interesting to investigate UV-B-induced changes in subcellular compartments to clarify the mechanisms leading to cell death in these cells.

\section{References}

Adachi, S., Minamisawa, K., Okushima, Y., Inagaki, S., Yoshiyama, K., Kondou, Y., et al. (2011). Programmed induction of endoreduplication by DNA doublestrand breaks in Arabidopsis. Proc. Natl. Acad. Sci. U.S.A. 108, 10004-10009. doi: 10.1073/pnas.1103584108

Ahmad, M., Jarillo, J. A., Klimczak, L. J., Landry, L. G., Peng, T., Last, R. L., et al. (1997). An enzyme similar to animal type II photolyases mediates photoreactivation in Arabidopsis. Plant Cell. 9, 199-207. doi: 10.1105/tpc.9.2.199

Allen, D. J., Mckee, I. F., Farage, P. K., and Baker, N. R. (1997). Analysis of limitations to $\mathrm{CO} 2$ assimilation on exposure of leaves of two Brassica napus cultivars to UV-B. Plant Cell Environ. 20, 633-640 doi: 10.1111/j.13653040.1997.00093.x

Amiard, S., Gallego, M. E., and White, C. I. (2013). Signaling of double strand breaks and deprotected telomeres in Arabidopsis. Front. Plant Sci. 4:405. doi: 10.3389/fpls.2013.00405

Anderson, H. J., Vonarx, E. J., Pastushok, L., Nakagawa, M., Katafuchi, A., Gruz, P., et al. (2008). Arabidopsis thaliana Y-family DNA polymerase eta catalyses translesion synthesis and interacts functionally with PCNA2. Plant J. 55, 895-908. doi: 10.1111/j.1365-313X.2008.03562.x

Arimura, S., Yamamoto, J., Aida, G. P., Nakazono, M., and Tsutsumi, N. (2004). Frequent fusion and fission of plant mitochondria with unequal nucleoid disruption. Proc. Natl. Acad. Sci. U.S.A. 101, 7805-7808. doi: 10.1073/pnas.0401077101
Although an expressed sequence tag clone library of BY-2 cells has been established (Matsuoka et al., 2004; Gális et al., 2006), the complete tobacco genome sequence (unlike the Arabidopsis genome sequence) has not been available until recently, and this has limited molecular analysis in BY-2 cells. In 2014, the draft genome sequence of Nicotiana tabacum, which is the source of the BY-2 line, was published (Sierro et al., 2014). In future, this information, coupled with use of the BY-2 cell model, may help to clarify in detail how UV-B affects plant cells, from the initial signaling events to cellular responses to UV-B irradiation.

In this study, we used an experimental model to investigate temporal changes in UV-B-induced damage responses in BY2 cells. Our results suggest that DNA damage mediates UV-B dose-dependent responses that affect cell cycle regulation and cell death.

\section{Acknowledgments}

The authors thank Dr. Nobuyoshi Nakajima (National Institute for Environmental Studies), Dr. Kazuhito Matsuo (National Institute for Agro-Environmental Sciences), Dr. Yuichi Takeuchi (Tokai University), Dr. Shigeyuki Kawano (The University of Tokyo), Dr. Yasuhiro Kadota (RIKEN) and Dr. Takumi Higaki (The University of Tokyo) for their technical support and valuable suggestions. This work was supported by Japan Society for the Promotion of Science KAKENHI Grant No. 26340044 (to ST) and No. 24770038 (to NK).

\section{Supplementary Material}

The Supplementary Material for this article can be found online at: http://journal.frontiersin.org/article/10.3389/fpls.2015. 00254/abstract

Biever, J. J., Brinkman, D., and Gardner, G. (2014). UV-B inhibition of hypocotyl growth in etiolated Arabidopsis thaliana seedlings is a consequence of cell cycle arrest initiated by photodimer accumulation. J. Exp. Bot. 65, 2949-2961. doi: 10.1093/jxb/eru035

Brown, B. A., and Jenkins, G. I. (2008). UV-B signaling pathways with different fluence-rate respose profiles are distinguished in mature arabidopsis leaf tissue by requirement for UVR8, HY5, and HYH. Plant Physiol. 146, 576-588 doi: 10.1104/pp.107.108456

Cimprich, K. A., and Cortez, D. (2008). ATR: an essential regulator of genome integrity. Nat. Rev. Mol. Cell. Biol. 9, 616-627. doi: 10.1038/nrm2450

Conney, A. H., Lu, Y. P., Lou, Y. R., Kawasumi, M., and Nghiem, P. (2013). Mechanisms of caffeine-induced inhibition of UVB carcinogenesis. Front. Oncol. 3:144. doi: 10.3389/fonc.2013.00144

Culligan, K., Tissier, A., and Britt, A. (2004). ATR regulates a G2-phase cellcycle checkpoint in Arabidopsis thaliana. Plant Cell 16, 1091-1104. doi: 10.1105/tpc.018903

Curtis, M. J., and Hays, J. B. (2011). Cooperative responses of DNA-damageactivated protein kinases ATR and ATM and DNA translesion polymerases to replication-blocking DNA damage in a stem-cell niche. DNA Repair 10, 1272-1281. doi: 10.1016/j.dnarep.2011.10.001

de Lima-Bessa, K. M., Armelini, M. G., Chigancas, V., Jacysyn, J. F., AmaranteMendes, G. P., Sarasin, A., et al. (2008). CPDs and 6-4PPs play different roles in UV-induced cell death in normal and NER-deficient human cells. DNA Repair 7, 303-312. doi: 10.1016/j.dnarep.2007.11.003 
Fulcher, N., and Sablowski, R. (2009). Hypersensitivity to DNA damage in plant stem cell niches. Proc. Natl. Acad. Sci. U.S.A. 106, 20984-20988. doi: 10.1073/pnas.0909218106

Furukawa, T., Curtis, M. J., Tominey, C. M., Duong, Y. H., Wilcox, B. W., Aggoune, D., et al. (2010). A shared DNA-damage-response pathway for induction of stem-cell death by UVB and by gamma irradiation. DNA Repair 9, 940-948. doi: 10.1016/j.dnarep.2010.06.006

Gális, I., Šimek, P., Sasaki, M., Horiguchi, T., Fukuda, H., Matsuoka, K., et al. (2006). A novel R2R3 MYB transcription factir NtMYBJS1 is a methyl jasmonate-dependent regulator of phenylpropanoid-conjugated biosynthesis in tobacco. Plant J. 46, 573-592 doi: 10.1111/j.1365-313X.2006.02719.x

Garcia, V., Bruchet, H., Camescasse, D., Granier, F., Bouchez, D., and Tissier, A. (2003). AtATM is essential for meiosis and the somatic response to DNA damage in plants. Plant Cell 15, 119-132. doi: 10.1105/tpc.006577

Gardner, G., Lin, C., Tobin, E. M., Loehrer, H., and Brinkman, D. (2009). Photobiological properties of the inhibition of etiolated Arabidopsis seedling growth by ultraviolet-B irradiation. Plant Cell Environ. 32, 1573-1583. doi: 10.1111/j.1365-3040.2009.02021.x

Garinis, G. A., Mitchell, J. R., Moorhouse, M. J., Hanada, K., De Waard, H., Vandeputte, D., et al. (2005). Transcriptome analysis reveals cyclobutane pyrimidine dimers as a major source of UV-induced DNA breaks. EMBO J. 24, 3952-3962. doi: 10.1038/sj.emboj.7600849

Gavrieli, Y., Sherman, Y., and Ben-Sasson, S. A. (1992). Identification of programmed cell death in situ via specific labeling of nuclear DNA fragmentation. J. Cell. Biol. 119, 493-501 doi: 10.1083/jcb.119.3.493

Hada, M., Iida, Y., and Takeuchi, Y. (2000). Action spectra of DNA photolyases for photorepair of cyclobutane pyrimidine dimers in sorghum and cucumber. Plant Cell Physiol. 41, 644-648. doi: 10.1093/pcp/41.5.644

Hidema, J., Kumagai, T., and Sutherland, B. M. (2000). UV radiation-sensitive norin 1 rice contains defective cyclobutane pyrimidine dimer photolyase. Plant Cell 12, 1569-1578. doi: 10.1105/tpc.12.9.1569

Higaki, T., Goh, T., Hayashi, T., Kutsuna, N., Kadota, Y., Hasezawa, S., et al. (2007). Elicitor-induced cytoskeletal rearrangement relates to vacuolar dynamics and execution of cell death: in vivo imaging of hypersensitive cell death in tobacco BY-2 cells. Plant Cell Physiol. 48, 1414-1425. doi: 10.1093/pcp/pcm109

Ioki, M., Takahashi, S., Nakajima, N., Fujikura, K., Tamaoki, M., Saji, H., et al. (2008). An unidentified ultraviolet-B-specific photoreceptor mediates transcriptional activation of the cyclobutane pyrimidine dimer photolyase gene in plants. Planta 229, 25-36. doi: 10.1007/s00425-008-0803-4

Jiang, L., Wang, Y., Bjorn, L. O., and Li, S. (2011). UV-B-induced DNA damage mediates expression changes of cell cycle regulatory genes in Arabidopsis root tips. Planta 233, 831-841. doi: 10.1007/s00425-010-1340-5

Kadota, Y., Furuichi, T., Sano, T., Kaya, H., Gunji, W., Murakami, Y., et al. (2005). Cell-cycle-dependent regulation of oxidative stress responses and $\mathrm{Ca}^{2+}$ permeable channels NtTPC1A/B in tobacco BY-2 cells. Biochem. Biophys. Res. Commun. 336, 1259-1267. doi: 10.1016/j.bbrc.2005.09.004

Kumagai-Sano, F., Hayashi, T., Sano, T., and Hasezawa, S. (2006). Cell cycle synchronization of tobacco BY-2 cells. Nat. Protoc. 1, 2621-2627. doi: 10.1038/nprot.2006.381

Kusano, M., Tohge, T., Fukushima, A., Kobayashi, M., Hayashi, N., Otsuki, H., et al. (2011). Metabolomics reveals comprehensive reprogramming involving two independent metabolic responses of Arabidopsis to UV-B light. Plant J. 67, 354-369. doi: 10.1111/j.1365-313X.2011.04599.x

Kwon, Y. I., Abe, K., Endo, M., Osakabe, K., Ohtsuki, N., Nishizawa-Yokoi, A., et al. (2013). DNA replication arrest leads to enhanced homologous recombination and cell death in meristems of rice OsRecQ14 mutants. BMC Plant Biol. 13:62. doi: 10.1186/1471-2229-13-62

Lo, H. L., Nakajima, S., Ma, L., Walter, B., Yasui, A., Ethell, D. W., et al. (2005). Differential biologic effects of CPD and 6-4PP UV-induced DNA damage on the induction of apoptosis and cell-cycle arrest. BMC Cancer 5:135. doi: 10.1186/1471-2407-5-135

Lopes, M., Foiani, M., and Sogo, J. M. (2006). Multiple mechanisms control chromosome integrity after replication fork uncoupling and restart at irreparable UV lesions. Mol. Cell. 21, 15-27. doi: 10.1016/j.molcel.2005. 11.015

Lytvyn, D. I., Yemets, A. I., and Blume, Y. B. (2010). UV-B overexposure induces programmed cell death in a BY-2 tobacco cell line. Environ. Exp. Bot. 68, 51-57. doi: 10.1016/j.envexpbot.2009.11.004
Mannuss, A., Trapp, O., and Puchta, H. (2012). Gene regulation in response to DNA damage. Biochim. Biophys. Acta 1819, 154-165. doi: 10.1016/j.bbagrm.2011.08.003

Matsuoka, K., Demura, T., Galis, I., Horiguchi, T., Sasaki, N., Tashiro, G., et al. (2004). A comprehensive gene expression aanalysis toward the understanding of growth and differentiation of tobacco BY-2 cells. Plant Cell Physiol. 45, 1280-1289. doi: $10.1093 / \mathrm{pcp} / \mathrm{pch} 155$

Menke, M., Chen, I., Angelis, K. J., and Schubert, I. (2001). DNA damage and repair in Arabidopsis thaliana as measured by the comet assay after treatment with different classes of genotoxins. Mutat. Res. 493, 87-93. doi: 10.1016/S13835718(01)00165-6

Nagata, T., Nemoto, Y., and Hasezawa, S. (1992). Tobacco By-2 cell line as the "HeLa" cell in the cell biology of higher plants. Int. Rev. Cytol. 132, 1-30. doi: 10.1016/S0074-7696(08)62452-3

Nakajima, S., Sugiyama, M., Iwai, S., Hitomi, K., Otoshi, E., Kim, S. T., et al. (1998). Cloning and characterization of a gene (UVR3) required for photorepair of 64 photoproducts in Arabidopsis thaliana. Nucleic Acids Res. 26, 638-644. doi: $10.1093 /$ nar $/ 26.2 .638$

Ohno, R., Kadota, Y., Fujii, S., Sekine, M., Umeda, M., and Kuchitsu, K. (2011). Cryptogein-Induced cell cycle arrest at G2 phase is associated with inhibition of cyclin-dependent kinases, suppression of expression of cell cycle-related genes and protein degradation in synchronized tobacco BY-2 cells. Plant Cell Physiol. 52, 922-932. doi: 10.1093/pcp/pcr042

Ortolan, T. G., and Menck, C. F. (2013). UVB-induced cell death signaling is associated with G1-S progression and transcription inhibition in primary human fibroblasts. PLOS ONE 8:e76936. doi: 10.1371/journal.pone. 0076936

Perennes, C., Glab, N., Guglieni, B., Doutriaux, M. P., Phan, T. H., Planchais, S., et al. (1999). Is $\operatorname{arcA3}$ a possible mediator in the signal transduction pathway during agonist cell cycle arrest by salicylic acid and UV irradiation? J. Cell Sci. $112,1181-1190$

Radziejwoski, A., Vlieghe, K., Lammens, T., Berckmans, B., Maes, S., Jansen, M. A., et al. (2011). Atypical E2F activity coordinates PHR1 photolyase gene transcription with endoreduplication onset. EMBO J. 30, 355-363. doi: 10.1038/emboj.2010.313

Ries, G., Buchholz, G., Frohnmeyer, H., and Hohn, B. (2000). UV-damagemediated induction of homologous recombination in Arabidopsis is depend on photosynthetically active radiation. Proc. Natl. Acad. Sci. U.S.A. 97, 13425-13429. doi: 10.1073/pnas.230251897

Roy, S. (2014). Maintenance of genome stability in plants: repairing DNA double strand breaks and chromatin structure stability. Front. Plant Sci. 5:487. doi: 10.3389/fpls.2014.00487

Sakamoto, A., Lan, V. T., Hase, Y., Shikazono, N., Matsunaga, T., and Tanaka, A. (2003). Disruption of the AtREV3 gene causes hypersensitivity to ultraviolet B light and gamma-rays in Arabidopsis: implication of the presence of a translesion synthesis mechanism in plants. Plant Cell 15, 2042-2057. doi: $10.1105 /$ tpc. 012369

Sakamoto, A. N., Lan, V. T., Puripunyavanich, V., Hase, Y., Yokota, Y., Shikazono, N., et al. (2009). A UVB-hypersensitive mutant in Arabidopsis thaliana is defective in the DNA damage response. Plant J. 60, 509-517. doi: 10.1111/j.1365313X.2009.03974.x

Sano, T., Higaki, T., Handa, K., Kadota, Y., Kuchitsu, K., Hasezawa, S., et al. (2006). Calcium ions are involved in the delay of plant cell cycle progression by abiotic stresses. FEBS Lett. 580, 597-602. doi: 10.1016/j.febslet.2005.12.074

Sano, T., Higaki, T., Oda, Y., Hayashi, T., and Hasezawa, S. (2005). Appearance of actin microfilament 'twin peaks' in mitosis and their function in cell plate formation, as visualized in tobacco BY-2 cells expressing GFP-fimbrin. Plant J. 44, 595-605 doi: 10.1111/j.1365-313X.2005.02558.x

Shiloh, Y., and Ziv, Y. (2013). The ATM protein kinase: regulating the cellular response to genotoxic stress, and more. Nat. Rev. Mol. Cell. Biol. 14, 197-210. doi: $10.1038 / \mathrm{nrm} 3546$

Sierro, N., Battey, J. N. D., Ouadi, S., Bakaher, N., Bovet, L., Willig, A., et al. (2014). The tobacco genome sequnece and its comparision with those of tomato and potato. Nat. Commun. 5, 3833. doi: 10.1038/ncomms 4833

Smetana, O., Siroky, J., Houlne, G., Opatrny, Z., and Chaboute, M. E. (2012). Nonapoptotic programmed cell death with paraptotic-like features in bleomycintreated plant cells is suppressed by inhibition of ATM/ATR pathways or NtE2F overexpression. J. Exp. Bot. 63, 2631-2644. doi: 10.1093/jxb/err439 
Takahashi, S., Nakajima, N., Saji, H., and Kondo, N. (2002). Diurnal change of cucumber CPD photolyase gene (CsPHR) expression and its physiological role in growth under UV-B irradiation. Plant Cell Physiol. 43, 342-349. doi: $10.1093 / \mathrm{pcp} / \mathrm{pcf038}$

Takahashi, S., Sakamoto, A., Sato, S., Kato, T., Tabata, S., and Tanaka, A. (2005). Roles of Arabidopsis AtREV1 and AtREV7 in translesion synthesis. Plant Physiol. 138, 870-881. doi: 10.1104/pp.105.060236

Takasawa, R., Nakamura, T., Mori, T, and Tanuma, S. (2005). Differential apoptotic pathways in human keratinocyte HaCaT Cells exposed to UVB and UVC. Apoptosis 10, 1121-1130. doi: 10.1007/s10495-005-0901-8

Takeuchi, A., Yamaguchi, T., Hidema, J., Strid, A., and Kumagai, T. (2002). Changes in synthesis and degradataion of Rubisco and LHCII with leaf age in rice (Oryza sativa L.) growing under supplementary UV-B radiation. Plant Cell Environ. 25, 695-706 doi: 10.1046/j.1365-3040.2002.00844.x

Takeuchi, Y., Inoue, T., Takemura, K., Hada, M., Takahashi, S., Ioki, M., et al. (2007). Induction and inhibition of cyclobutane pyrimidine dimer photolyase in etiolated cucumber (Cucumis sativus) cotyledons after ultraviolet irradiation depends on wavelength. J. Plant Res. 120, 365-374. doi: 10.1007/s10265-0060065-9

Takeuchi, Y., Murakami, M., Nakajima, N., Kondo, N., and Nikaido, O. (1996). Induction and repair of damage to DNA in cucumber cotyledons irradiated with UV-B. Plant Cell Physiol. 37, 181-187. doi: 10.1093/oxfordjournals.pcp.a028930

Teranishi, M., Nakamura, K., Morioka, H., Yamamoto, K., and Hidema, J. (2008). The native cyclobutane pyrimidine dimer photolyase of rice is phosphorylated. Plant Physiol. 146, 1941-1951. doi: 10.1104/pp.107.110189
Yasuhara, H., and Kitamoto, K. (2014). Aphidicolin-induced nuclear elongation in tobacco BY-2 cells. Plant Cell Physiol. 55, 913-927. doi: 10.1093/pcp/ pcu026

Yoshiyama, K., Conklin, P. A., Huefner, N. D., and Britt, A. B. (2009). Suppressor of gamma response 1 (SOG1) encodes a putative transcription factor governing multiple responses to DNA damage. Proc. Natl. Acad. Sci. U.S.A. 106, 12843-12848. doi: 10.1073/pnas.0810304106

Yoshiyama, K. O., Kobayashi, J., Ogita, N., Ueda, M., Kimura, S., Maki, H., et al. (2013a). ATM-mediated phosphorylation of SOG1 is essential for the DNA damage response in Arabidopsis. EMBO Rep. 14, 817-822. doi: 10.1038/embor.2013.112

Yoshiyama, K. O., Sakaguchi, K., and Kimura, S. (2013b). DNA damage response in plants: conserved and variable response compared to animals. Biology 2, 1338-1356. doi: 10.3390/biology2041338

Conflict of Interest Statement: The authors declare that the research was conducted in the absence of any commercial or financial relationships that could be construed as a potential conflict of interest.

Copyright (c) 2015 Takahashi, Kojo, Kutsuna, Endo, Toki, Isoda and Hasezawa. This is an open-access article distributed under the terms of the Creative Commons Attribution License (CC BY). The use, distribution or reproduction in other forums is permitted, provided the original author(s) or licensor are credited and that the original publication in this journal is cited, in accordance with accepted academic practice. No use, distribution or reproduction is permitted which does not comply with these terms. 